\title{
CAUGHT IN THE MIDDLE: THE BIAS AGAINST STARTUP INNOVATION WITH TECHNICAL AND COMMERCIAL CHALLENGES
}

\author{
Ashish Arora \\ Andrea Fosfuri \\ Thomas Roende \\ Working Paper 29654 \\ http://www.nber.org/papers/w29654 \\ NATIONAL BUREAU OF ECONOMIC RESEARCH \\ 1050 Massachusetts Avenue \\ Cambridge, MA 02138 \\ January 2022
}

We thank Sharon Belenzon, Raman Nanda, Lars Persson, and seminar participants at IFN Stockholm, and Harvard Business School, for comments and suggestions. The views expressed herein are those of the authors and do not necessarily reflect the views of the National Bureau of Economic Research.

NBER working papers are circulated for discussion and comment purposes. They have not been peer-reviewed or been subject to the review by the NBER Board of Directors that accompanies official NBER publications.

(C) 2022 by Ashish Arora, Andrea Fosfuri, and Thomas Roende. All rights reserved. Short sections of text, not to exceed two paragraphs, may be quoted without explicit permission provided that full credit, including $\odot$ notice, is given to the source. 
Caught In The Middle: The Bias Against Startup Innovation With Technical And Commercial

Challenges

Ashish Arora, Andrea Fosfuri, and Thomas Roende

NBER Working Paper No. 29654

January 2022

JEL No. L26,O31,Q55

\section{ABSTRACT}

Startups in IT and life sciences appear to be flourishing. However, startups in other sectors, such as new materials, automation, and eco-innovations, which are often called "deep tech", seem to struggle. We argue that innovations with both technical and commercial challenges, typical of deep tech innovations, are especially disadvantaged in a startup-based innovation system. We develop an analytical model where startups are more efficient at solving technical challenges and incumbents are more efficient at solving commercial challenges. We find that the startup-based system works better for "specialized" innovations, where only one type of challenges is significant. Startups which face both technical and commercial challenges are disadvantaged because they capture a smaller fraction of the value they create. We discuss the implications for various public policies that have been proposed to encourage deep-tech.

Ashish Arora

Fuqua School of Business

Duke University

Box 90120

Durham, NC 27708-0120

and NBER

ashish.arora@duke.edu

Andrea Fosfuri

Bocconi University

Department of Management \& Technology

Via Roentgen 1

20136 Milan, Italy

andrea.fosfuri@unibocconi.it
Thomas Roende

Copenhagen Business School

Department of Innovation and

Organizational Economics

DK-2000 Frederiksberg,

Denmark

thr.ino@cbs.dk 


\section{Introduction}

The innovation ecosystem in America increasingly consists of a division of innovative labor between startups (which develop new inventions, often based on university discoveries) and incumbents, which acquire the inventions and commercialize them (Arora, Belenzon, Patacconi, and Suh, 2020). ${ }^{1}$ This system seems to work well for IT innovations, such as software and social media applications, and innovations in life sciences. However, many observers (BCG, 2021; Lerner and Nanda, 2020; Nanda, 2020) have pointed out that the startup-based system works less well in other sectors, such as new materials, automation, and eco-innovations, which are often called "deep tech".2

There are a number of explanations offered for why deep tech startups struggle to attract riskcapital. Their commercial success might depend on changes in regulations and the development of complementary infrastructure for which startups are less equipped to cope with (Janeway, 2018). Furthermore, the underlying technology for deep tech ventures may be expensive and difficult to de-risk (Nanda, 2020). Finally, there may also be frictions in the supply of risk capital for such ventures (Ewens, Nanda and Rhodes-Kropf, 2018; Lerner and Nanda, 2020). These explanations are all consistent with the empirical observation that, while the venture capital (VC) sector has been exuberant in recent years, investment in deep tech startups is lagging behind (BCG, 2021; Janeway, Nanda, and Rhodes-Kropf, 2021).

In this paper we offer a complementary explanation: the relative importance of technical and commercial challenges. We argue that an innovation ecosystem wherein one organizational type (startups) is better at solving technical challenges, and another organizational type (incumbents) is better at solving the commercial challenges will favor innovations that involve primarily one type of challenges. Innovation projects where both technical and commercial challenges are present will be disadvantaged and thus naturally less attractive to potential investors. Specifically, the inability to

\footnotetext{
${ }^{1}$ Most startups exit via acquisition by a large corporation (Cunningham, Ederer and Ma, 2021; Gans, Hsu and Stern, 2002; Henkel, Rønde and Wagner, 2015; Higgins and Rodriguez, 2006). The National Venture Capital Association reports that $82 \%$ of all US VC-backed exits in 2016 were acquisitions.

${ }^{2}$ Deep tech (also called hard tech or tough tech) innovation refers to complex technologies rooted in science and advanced engineering. Examples include new energy technologies such as small-scale nuclear reactors, new energy storage solutions, carbon capture technologies, synthetic biology-based production technologies that are environmentally friendly, and lab grown tissue.
} 
attract VC is a symptom of a deeper problem - deep tech startups are privately less valuable relative to the total value they create.

Two examples illustrate the combination of technical and commercial challenges that deep tech startups must solve. The traditional production of cement is energy intensive, and is estimated to account for 8\% of global $\mathrm{CO}_{2}$ emissions (https://www.chathamhouse.org/2018/06/making-concretechange-innovation-low-carbon-cement-and-concrete). Biomason is developing a way to grow cement bricks and tiles with bacteria to replace traditional cement. Founded in 2012, Biomason has raised \$23 million in funding, but has generated less than \$10 million in revenue. Developing the technology was difficult because it relied on engineering bacteria.

“We grew some bricks and thought, 'Okay, we've done it.' We thought, 'Okay, somebody is going to be interested in this who knows how to scale the technology and they're going to do it.' We realized very quickly that we were going to have to be the ones that did it."

(Ginger Dosier, CEO, Biomason) $)^{3}$

Finding customers and partners was equally challenging. Traditional cement companies were skeptical about the commercial viability of the technology. Though structural applications (i.e., cement bricks) were the largest market, customers were unwilling to bet on an unproven technology. The company has initially targeted niche applications such as tiles and dust-control in mining operations, and has survived through DARPA contracts. ${ }^{4}$

The history of iRobot, which introduced the autonomous home vacuum cleaner, Roomba, similarly highlights the difficulties for startups that face both technical and commercial challenges. The company was founded in 1990 by three members of MIT's Artificial Intelligence Lab, who designed robots for space exploration and military defense. When the company started its activities there were many unsolved technical challenges: Spatial navigation, voice recognition, machine vision, and the right mix of mechanical, electrical, and software engineering, connectivity, and data science, to name just a few. Most importantly, the market was still unclear. First, customers did not believe that a robot could do useful tasks in a way that it could replace humans. Second, there was great uncertainty on how customers would use robots once they could be convinced that they were

3 Quoted in Forbes https://www.forbes.com/sites/amyfeldman/2021/06/14/startup-biomason-makes-biocement-tiles-retailer-hm-group-plans-to-outfit-its-stores-floors-with-them.

${ }^{4}$ These include an underwater cement that could be used to protect the shoreline against erosion, and a defense subcontract for small landing pads for helicopters in remote locations. 
useful. ${ }^{5}$ While iRobot was founded in 1990, its first market success was with the launch of Roomba in 2002 whose sales reached 1 million units in 2004. iRobot went public in 2005. However, all the years from foundation till 2002, iRobot benefitted from substantial support from DARPA, and survived thanks to the military application of its robots. ${ }^{6}$

These examples highlight the combination of technical and commercial challenges that deep tech startups must solve. In this paper, we show that, other things equal, the combination of technical and commercial challenges hurts the bargaining position of the startup in negotiating the price of the acquisition. Consequently, the startup's expected value to potential investors is also lower. Stated otherwise, the division of innovative labor between technology startups and incumbents is especially inefficient for deep tech innovation.

The key assumption is that startups negotiate with incumbents only after the technical challenges are solved. This assumption corresponds with reality. It is also consistent with our model in which the fit of the startup's technology with an incumbent is ex-ante uncertain. Specifically, there are a number of possible incumbent firms that could successfully take the technology to market after it is developed, but which incumbent will be best positioned to do so is unknown before the technical challenges are addressed. This means that a contract with any given incumbent will not solve the problem. Potentially, all incumbents could join together to contract with the startup. Even discounting the potential anti-trust concerns, this option is very difficult to implement, particularly if the incumbents are in different sectors, as was the case with iRobot. Similarly, for Biomason, potential incumbents to contract with include producers of decorative tiles and building materials, military contractors, and cement producers.

Turning to related work, there is a large literature on the functioning and efficiency of markets for technology (Arora, Fosfuri, and Gambardella, 2001). Within this broad literature, our paper contributes to the rapidly growing stream of papers analyzing the consequences of acquisitions of high-tech startups by incumbents for issues such as R\&D choices (Färnstrand Damsgaard et al., 2017; Gans et al., 2002), exit strategies of entrepreneurs (Arora, Fosfuri and Rønde, 2021;

\footnotetext{
${ }^{5}$ The uncertainty about the use of the product generated huge costs for iRobot. For instance, their first robot vacuum cleaner, Roomba, was built to match the reliability standards of European upright vacuums. Its customers, however, would often run it once per day, rather than the once per week average for the European standard set. As a consequence, the first generation of Roomba robots broke down two years ahead of schedule, hurting its reputation.

${ }^{6}$ For instance, in 1996, iRobot released Ariel, a crab-like robot designed to remove mines.
} 
Ransbotham and Mitra, 2010) and the consolidation of market power (Cunningham et al., 2020; Fumagalli, Motta and Tarantino, 2020). However, this paper represents - to the best of our knowledge - the first analysis of how the allocation of costs across the different stages of the R\&D process affects the division of innovative labor between startups and incumbents.

Closer to our work, the importance of upfront investments in solving technical challenges and of uncertainty regarding the later uses of a technology feature prominently in the pioneering work of Green and Scotchmer (1995). They consider the case where an initial innovation makes possible additional innovations, in an industry distinct from that of the initial innovation. The assumption that ex ante contracts are not possible is also foundational in their work, and they focus instead on how patent breadth (and length) affects the division of rents between the two innovators and, hence, the incentives of the two parties. ${ }^{7}$

Our model differs in a couple of important ways. First, the initial innovator in our model, the startup, can potentially also carry out the second task - namely the follow-on application in Green and Scotchmer (1995). More precisely, we assume that either the startup can solve the commercial challenges itself, or potentially also seek other firms to do so. These outside options, however, entail a higher cost of solving the commercial challenges than that of the focal incumbent, who corresponds to the second innovator in Green and Scotchmer (1995).

This is related to the second way in which our model departs from theirs, which is the relative size of the initial and follow-on investment. This is important because when the follow-on investment is small, the inefficiency of the outside option matters less, thereby improving the bargaining position of the startup. On the other hand, when the initial investment in solving the technical challenges is small relative to the investment in addressing the commercial challenges, though the startup's outside options are unattractive, its upfront cost is also lower. Instead, when the technical and commercial challenges are comparable in size, the startup is "caught in the middle”: The outside options are unattractive but the upfront costs are still substantial. These seemingly minor differences nonetheless result in a novel explanation for why deep tech innovation receives insufficient VC funding, namely that deep-tech startups are able to capture a smaller fraction of the value they create.

\footnotetext{
${ }^{7}$ As they put it, "Although such agreements could achieve first-best incentives for research in our model, they would be difficult to negotiate; prior to invention of the first technology, it is difficult for the first innovator to identify the firms that will think of second-generation products. (p 23)”
} 
Our explanation for the inability of deep tech startups to attract sufficient VC funding also differs from existing accounts. One popular explanation focuses on the greater time and investment requirements of deep tech ventures (BCG, 2021). The simplest version of this explanation seems to suggest that such projects have low expected payoffs. The empirical basis for this assertion is unclear, but if true, it implies that these projects would also not be undertaken by established firms. That is, this explanation does not speak to the debate of whether deep tech startups are somehow disadvantaged relative to incumbents. A related argument, which does pertain to startups, asserts that the VC system is biased against projects with longer time horizons and large upfront investments, or projects with high scientific or technical uncertainty (Lerner and Nanda, 2020). However, these different arguments cannot fully explain why so much VC money has been sunk into biotech, an industry faced with high technical challenges, large-scale investments and longtime horizons. In biotech, if a given project is successful in addressing the technical challenges (i.e. does the drug work?), there will not be much uncertainty about the existence of demand and the commercialization pathway. Thus, while biotech is confronted with huge technical challenges, the commercial challenges appear modest, which, according to our theory, explains why VC support in this industry has been readily forthcoming.

Nanda (2020) have highlighted the problem of de-risking the technology. Simply put, some projects take longer and more money before the uncertainty about its commercial prospects is low enough to merit large scale investment in scale up and commercialization. By contrast, in other cases, a small investment in an early stage venture can produce enough information whereby the venture is either shut down or additional investments can be made. Ewens et al. (2018) argue that VCs may forgo investing in the ability to evaluate early stage startups. Instead VCs may adopt a "spray and pray" approach, wherein they finance a large number of early stage startups and wait to see which experiments are successful. In this view, the reduction in the cost of experimenting, made possible by the rise of technologies such as cloud-computing, is shifting the focus of investors towards software ventures where small early investments quickly resolve much of the uncertainty, and away from deep tech and other ventures where the uncertainty takes more time and money to resolve. Importantly, the possibility of low-cost experiments creates an option value to investing, so that software ventures are more valuable than ventures where low-cost de-risking is not possible. By contrast, in our baseline model, all projects have the same expected value, and there is no uncertainty creating an option value from investing in solving the technical challenges. By 
introducing another player, the incumbent who will potentially acquire the startup, we highlight the importance of how value is shared between the startup and the incumbent. Although VC is not explicitly featured in our model, we implicitly assume that startups are valued using the same standard. Startups that can expect to capture a larger share of the value they create will get higher valuations. Competition among VCs would ensure that VCs would be indifferent between all positive NPV projects. Negative NPV projects would not, naturally, attract any investors, and nor would any rational entrepreneur wish to start a negative NPV venture.

In a study of American medical device startups over a 25-year period, Fischer, Henkel and Stern (2020) find that $72 \%$ of the startups in the sample were acquired, and conditional on acquisition, 86\% were acquired after FDA approval, i.e., after the technical challenges were solved. Importantly, they find that pioneering startups have to wait longer, even conditional on FDA approval, to be acquired. Fischer et al. (2020) argue that the delay is because of the greater commercial challenges for devices that are the first of their type. This is similar in spirit to pioneers being caught in the middle. However, whereas we compare startups with the same net value creation in an environment of symmetric information, it is possible that pioneers have higher value creation and face greater informational asymmetries.

The rest of paper is organized as follows: Section 2 describes the baseline model. Section 3 derives the equilibrium of the model, establishes our main result, and performs comparative statics with respect to the parameters of the model. Section 4 discusses policies targeted at deep tech startups, and Section 5 outlines different extensions and robustness checks. Finally, Section 6 summarizes our results and concludes. Omitted proofs of the formal propositions are provided in the Appendix.

\section{Setup of the model}

All projects have both technical and commercial challenges that need to be addressed in order to create value. Let $u \in[0,1]$ represents the extent to which a project displays technical challenges relative to commercial challenges. Thus, $u=1$ captures a project with only technical challenges, while $u=0$ captures a project with only commercial challenges. Intermediate values of $u$ represent projects with both challenges.

We treat $u$ as a feature of the industry or technological field. Some fields have primarily technical challenges to address (for instance, biotech), while others have mainly commercial challenges (for instance, software). Finally, some have both types of challenges in similar proportions. As we have 
argued in the introduction, many fields that are considered part of deep tech like, for instance, robotics, energy storage, carbon capture and sequestration, alternative energy, and new materials, fall into this category.

For any given $u$, there is a startup and $n \geq 1$ large corporations (which we shall refer to as incumbents). Only the startup can solve the technical challenges (we relax this assumption in an extension below). Let $T(u)$ be the cost of addressing the technical challenges, with $T^{\prime}(u)>0$. Thus, higher values of $u$ imply greater costs of addressing the technical challenges.

Once the startup has addressed the technical challenges, it can either solve the commercial challenges by itself or be acquired by an incumbent that subsequently solves the commercial challenges. We assume that incumbents are heterogeneous in their ability to solve the commercial challenges of the project. That is, the match between the startup and a given incumbent matters for value creation. For instance, each incumbent might have an established go-to-market strategy that will be more or less well suited for the startup's project. The resolution of the technical challenges might bring the project closer to the downstream capabilities of a given incumbent, thus reducing its cost of addressing the commercial challenges. For instance, iRobot's demining robot is best commercialized by a defense contractor, but its room-cleaning robot would probably be better placed with a domestic appliances company.

To model this notion, we assume that incumbents are equidistantly located in a circle with circumference equal to 1 . After addressing the technical challenges, the startup's project falls on the location of one of the incumbents (in an extension later we allow the startup's project to fall on any point on the circle). The probability of falling on a given incumbent is uniform across incumbents and equal to $1 / n$. An incumbent's cost of addressing the commercial challenges is $C(u)(1+x)$ with $C^{\prime}(u)<0$. Hence, higher values of $u$ imply lower costs of addressing the commercial challenges. Also, $x$ is the distance between the incumbent and the startup. The closest incumbent $(x=0)$ and the second-closest incumbents $(x=1 / n)$ can solve the commercial challenges at costs of $C(u)$ and $C(u)\left(1+\frac{1}{n}\right)$, respectively. Alternatively, the startup can address the commercial challenges by itself at a cost $C(u)(1+\gamma)$ with $\gamma>0$ representing the relative disadvantage of the startup in solving the commercial challenges. Notice that there are always gains from trade: The most efficient way to profit from the project is by selling the startup to the closest incumbent. 
We assume that all projects have the same net social value defined as the value that the technology creates minus the total cost of developing it. All technologies have value $v$. They also have the same total costs but differ in the distribution of these costs (i.e. upfront investment in solving the technical challenges vs follow-on investment in addressing the commercial challenges).

Assumption 1. The net social value of a project $S \equiv v-(T(u)+C(u))$ is positive and constant in $u$ when developed in the most efficient way: $S>0$ and $T^{\prime}(u)+C^{\prime}(u)=0$.

Assumption 1 means that we are effectively analyzing differences in outcome for projects that are ex ante identical in terms of social value, albeit with different composition of costs. An increase in $u$ shifts costs from the follow-on investment in commercialization to the upfront investment in making the technology work, keeping total costs constant. Hence, projects characterized by low $u$ are backloaded whereas projects characterized by high $u$ are frontloaded. For simplicity of exposition and, in order to reduce the number of different cases, let $T(0)=C(1)=0$.

Notice that we assume away uncertainty regarding the value $v$ and the cost of solving the commercial challenges $C(u)$ that could introduce an option value of investing in solving the technical challenges that would depend on $u$ (we introduce uncertainty in an extension below). Furthermore, before solving the technical challenges, the startup does not know which incumbent is the closest ex-post. We assume that this uncertainty precludes ex-ante contracting. Thus, the startup can negotiate a deal with a potential incumbent only after the technical challenges have been addressed.

Turning to the acquisition of the startup, we assume that with probability $\frac{1}{2}$ the startup makes a takeit-or-leave-it offer to the closest incumbent, while with probability $\frac{1}{2}$ the incumbents make a take-itor-leave-it offer to the startup. In this latter case, only the offers of the closest and the two secondclosest incumbents matter. In order to ensure an equilibrium in pure strategies, it is assumed that if two or more bidders bid the same amount, the bidder with the highest willingness to pay acquires the startup. ${ }^{8}$

\footnotetext{
${ }^{8}$ In the analysis, we refer to the startup being acquired. However, the unit of analysis is a technology. Hence, the model can also be interpreted as the incumbents competing to acquire a technology developed by a startup.
} 


\section{Solving the model}

Suppose that a startup has invested $T(u)$ in solving the technical challenges. When the startup is sold to an incumbent, the parties involved foresee the cost of addressing the commercial challenges.

Hence, the value of the project is $v-C(u)$ to the closest incumbent, $\operatorname{Max}\left\{v-C(u)\left(1+\frac{1}{n}\right), 0\right\}$ to the second-closest incumbents, and $\operatorname{Max}\{v-C(u)(1+\gamma), 0\}$ to the startup itself. There are no frictions at the acquisition stage (see below). Thus, in equilibrium, the startup is always acquired by the closest incumbent as this maximizes the gains from trade.

The acquisition price is the value to the closest incumbent when the startup makes the offer, $v$ $C(u)$. When the incumbents make the offers, the closest incumbent makes the winning bid in equilibrium. The winning incumbent matches the startup’s best alternative. The second-closest incumbents bid as aggressively as they can in equilibrium and offer the price $\operatorname{Max}\{v-$ $\left.C(u)\left(1+\frac{1}{n}\right), 0\right\} .{ }^{9}$ Defining the variable $\theta \equiv \operatorname{Min}\left\{\gamma, \frac{1}{n}\right\}$, the startup's best alternative can be written as $\operatorname{Max}\{v-C(u)(1+\theta), 0\}$. Define: $u^{*}: v-(1+\theta) C(u)=0 \Leftrightarrow u^{*}=C^{-1}\left(\frac{v}{1+\theta}\right){ }^{10}$ Note that $u^{*}$ is implicitly defined by the condition that the rate of return conditional on the technical challenges being solved is equal to the gains from trade i.e., $\frac{v-C\left(u^{*}\right)}{C\left(u^{*}\right)}=\theta$. Notice that for $u>u^{*}$, the startup has a viable outside option. Instead, for $u<u^{*}$, the outside option for the startup is 0 . Thus, the outcome of the bargaining between the startup and the incumbent will change significantly whether $u$ is greater or smaller than $u^{*}$.

Assumption 2: $\frac{v-[C(u)+T(u)]}{[C(u)+T(u)]}<\theta$.

\footnotetext{
${ }^{9}$ We do not consider equilibria where the second-closest incumbents bid prices that are strictly above the value of the startup to them (but below the value of the startup to the closest incumbent). Such equilibria would, for instance, not exist if there were a very small but positive probability that the closest incumbent would be prevented from bidding for reasons outside of the model, see Tirole (1988).

${ }^{10}$ Our acquisition stage can also be interpreted as an alternating bargaining game between the startup and the closest incumbent in which the time period between offers is close to zero. Nevertheless, this interpretation influences which outside option is the relevant one to consider. Binmore, Rubinstein and Wolinsky (1986) show that if the risk of losing the gains from trade is what drives the parties to agree on an acquisition price, which seems plausible in a fast-moving technological area where the risk of being overtaken is prevalent, the relevant outside option in the bargaining process is the startup's cost of solving the commercial challenges, not the competing offers from the second-closest incumbents. However, our argument does not rely on the choice of a specific outside option for the startup.
} 
Assumption 2 implies the rate of return for the projects must be smaller than the gains from trade, represented by $\theta$. Given Assumption 2 and $C(0)=0, u^{*}$ is interior, i.e. $0<u^{*}<1$.

Let $\pi_{S}(u)$ and $\pi_{I}(u)$ denote the expected payoffs of the startup and the closest incumbent, respectively. We solve the game by looking separately at the two cases, $u \leq u^{*}$ and $u>u^{*}$. If $u \leq u^{*}$, the outside options of both the startup and the (closest) incumbent are equal to 0 .

$$
\begin{gathered}
\pi_{S}(u)=\frac{1}{2}[(v-C(u))-T(u)]+\frac{1}{2}[-T(u)]=\frac{1}{2}(S-T(u)) \\
\pi_{I}(u)=\frac{1}{2}[(v-C(u))]=\frac{1}{2}(S+T(u)) .
\end{gathered}
$$

If $u>u^{*}$, the outside option for the startup is $v-(1+\theta) C(u)$ and 0 for the (closest) incumbent. We can compute the following expected payoffs:

$$
\begin{gathered}
\pi_{S}(u)=\frac{1}{2}[v-C(u)-T(u)]+\frac{1}{2}[v-C(u)(1+\theta)-T(u)]=S-\frac{\theta}{2} C(u) \\
\pi_{I}(u)=\frac{\theta}{2} C(u) .
\end{gathered}
$$

If the startup does not invest in solving the technical challenges, all players get a payoff of zero for all values of $u$.

We now present the main result of the paper:

Proposition 1. [Caught in the middle] The value of the startup is the lowest for $u=u^{*}$. If $\frac{v-[C(u)+T(u)]}{[C(u)+T(u)]}<\frac{\theta}{2+\theta}$, there exists a region $u \in(\underline{u}, \bar{u})$ in which this value is strictly negative, $\underline{u}<$ $u^{*}<\bar{u}$.

Proof: Using equations (1) and (2), we have:

$$
\partial \pi_{S}(u) / \partial u=\left\{\begin{array}{lll}
-\frac{1}{2} T^{\prime}(u)<0 & \text { for } & u \leq u^{*} \\
-\frac{\theta}{2} C^{\prime}(u)>0 & \text { for } & u>u^{*}
\end{array}\right.
$$

Hence, $\pi_{S}(u)$ has a global minimum for $u=u^{*}$. Using $C\left(u^{*}\right)=\frac{v}{1+\theta}$ and continuity of $\pi_{S}(u)$ in $u$ we can rewrite the startup's profit for $u=u^{*}$ as:

$$
\pi_{S}\left(u^{*}\right)=S-\frac{1}{2} C\left(u^{*}\right)=v-[C(u)+T(u)]-\frac{v}{2(1+\theta)} .
$$


Solving for $\pi_{S}\left(u^{*}\right)<0$, we obtain the condition stated in the proposition. Notice also that Assumption 1 and $T(0)=0$ imply that $\pi_{S}(0)>0$. Furthermore, Assumption 1 and $C(1)=0$ imply that $\pi_{S}(1)>0$. Hence, if $\pi_{S}\left(u^{*}\right)<0$, it follows from equation (3) that there exist $\underline{u}$ and $\bar{u}$ where $\underline{u}<u^{*}<\bar{u}$ and where $\underline{u}$ and $\bar{u}$ are defined implicitly by $\pi_{S}(\underline{u})=\pi_{S}(\bar{u})=0$. Therefore, $\pi_{S}(u)<$ 0 for $\underline{u}<u<\bar{u}$.

Proposition 1 demonstrates that a startup is caught in the middle when the rate of return is sufficiently smaller than the gains from trade. The intuition behind the proposition is the following: Upfront investments by the startup in solving the technical challenges cause an ex-post hold up problem. When the startup cannot credibly threaten to go alone $\left(u \leq u^{*}\right)$, the holdup problem becomes less severe as $u$ declines. Conversely, when the project is mostly about solving technical challenges $\left(u>u^{*}\right)$, the holdup problem is partially mitigated because the startup has a viable, albeit less efficient, outside option. For higher values of $u$, the cost of solving the commercial challenges is smaller and the (closest) incumbent's commercialization advantage matters less. However, when the technical and commercial challenges are comparable, the startup is "caught in the middle”. Either it does not have an outside option and it will face a sizable holdup problem or it does have one, but its higher cost of solving the commercial challenges means that the incumbent can capture more of the gains from trade.

Notice that if there are financing frictions, or other types of cost per investment, low net present value (NPV) projects may go unfunded. For example, the expected returns may be outweighed by venture capitalists' mostly fixed costs of due-diligence, mentoring, and oversight or by the costs of incentivizing the founders (Holmström and Tirole, 1997). It is obvious that a higher required return on the side of investors would expand the area where socially valuable projects fail to receive funding.

Figure 1 below illustrates the profit function of the startup as a function of $u$ for the case of linear costs. 
Figure 1: Profit function of the startup $\pi_{s}(u)$ when $C(u)=1-u$ and $T(u)=u$. The parameters are $\theta=1$ and $v=1.2$ (solid line), $v=1.3$ (dashed line), and $v=1.4$ (dotted line).

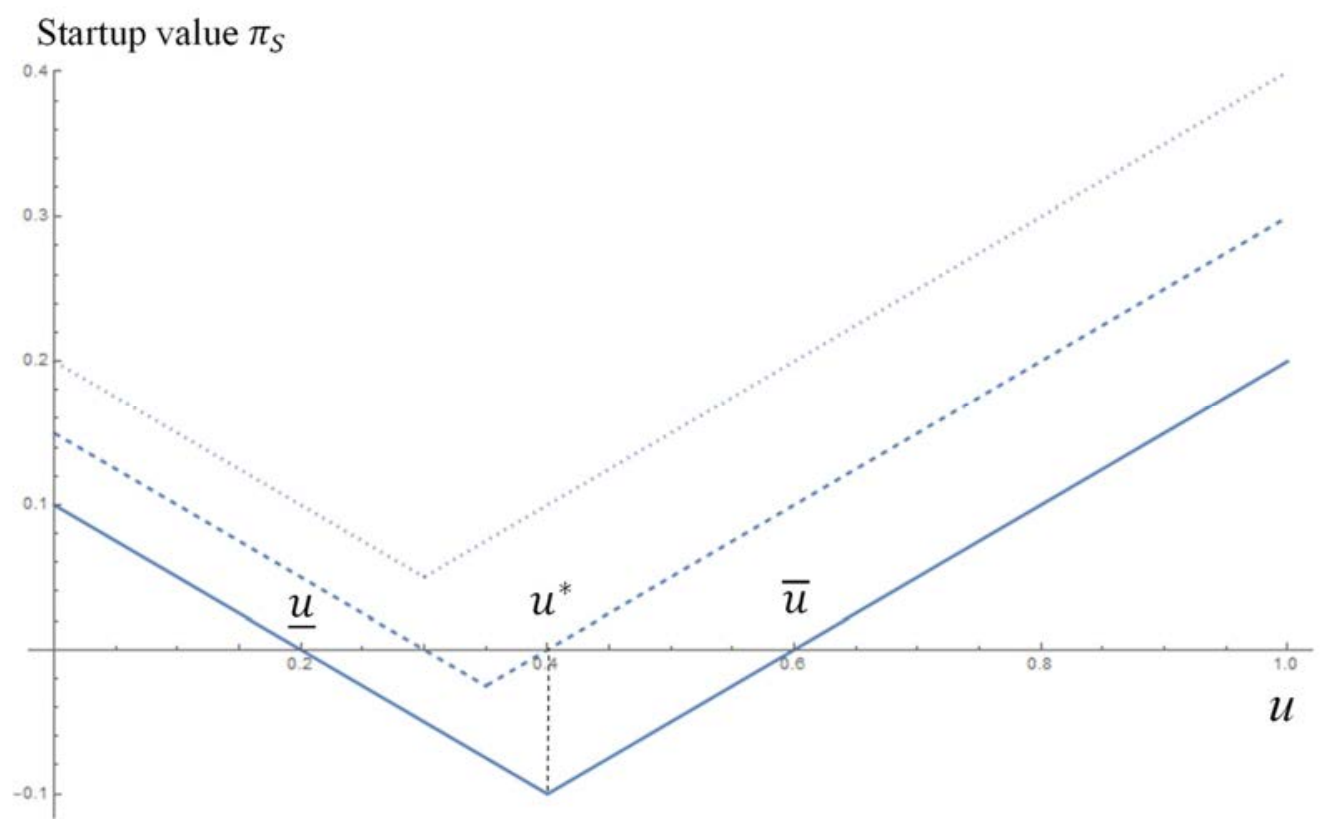

Figure 1 illustrates how the profit function of the startup has a global minimum at $u=u^{*}$.

Furthermore, if $(v-[C(u)+T(u)]) /[C(u)+T(u)]$ is below the threshold defined in Proposition 1 , there is a region of $u$ for which the startup's private return on the project is negative, $\pi_{S}(u)<0$. Hence, without public support these projects will not be realized, an issue that we discuss in the next section. Next proposition derives formally the comparative statics of the model.

Proposition 2. [Comparative statics] Consider $u^{*}$ and $\underline{u}$ and $\bar{u}$ as defined in Proposition 1. Let the total cost of solving both the technical and the commercial challenges be $(1+\beta)[C(u)+T(u)]$, $\beta \geq 0$. Then, the following holds:

$$
\begin{aligned}
& \text { i) } \quad \partial u^{*} / \partial v<0, \frac{\partial \underline{u}}{\partial v}>0 \text {, and } \partial \bar{u} / \partial v<0 \text {, } \\
& \text { ii) } \quad \partial u^{*} / \partial \theta>0, \frac{\partial \underline{u}}{\partial \theta}=0 \text {, and } \partial \bar{u} / \partial \theta>0 \text {. } \\
& \text { iii) } \quad \partial u^{*} / \partial \beta>0, \frac{\partial \underline{u}}{\partial \beta}<0 \text {, and } \partial \bar{u} / \partial \beta>0 \text {. }
\end{aligned}
$$

\section{Proof: See Appendix A.}

The effects of an increase in $v$ are illustrated in Figure 1. The profit function shifts up, reducing the size of the region of $u$ in which the return of the startup is negative. At the same time, an increase in 
$v$ implies that the startup's outside option, whether solving the commercial challenges by itself or selling the project to the second-closest incumbents, becomes profitable for a higher cost of addressing the commercial challenges, which explains why $u^{*}$ is decreasing in $v$.

A proportional increase in the costs of the addressing the commercial and technical challenges (i.e., an increase in $\beta$ ) has the opposite effects of an increase in $v$. It shifts the profit function of the startup down and makes the outside options of the startup less profitable. Hence, the region of $u$ in which the startup earns a negative return expands, and the threshold $u^{*}$ increases.

Finally, consider a worsening of the startup's outside options (i.e., an increase in $\theta$ ), which might be due to a greater comparative disadvantage of the startup in solving the commercial challenges or a reduction in the number of potential buyers. This matters only for $u \geq u^{*}$ (where the outside options influence the bargaining). Hence, as illustrated in Figure 2, an increase in $\theta$ rotates down the profit function for $u \geq u^{*}$ around the point $\left(u, \pi_{S}\right)=\left(1, \pi_{S}(1)\right)$. The threshold $u^{*}$ increases as a result of this, and the region of $u$ in which the startup earns a negative return expands for $u>u^{*}$.

Figure 2: The expected value of the startup $\pi_{s}(u)$ when $C(u)=1-u$ and $T(u)=u$. The parameters are $v=1.2, \theta=0.8$ (solid line) and $\theta=1$ (dashed line).

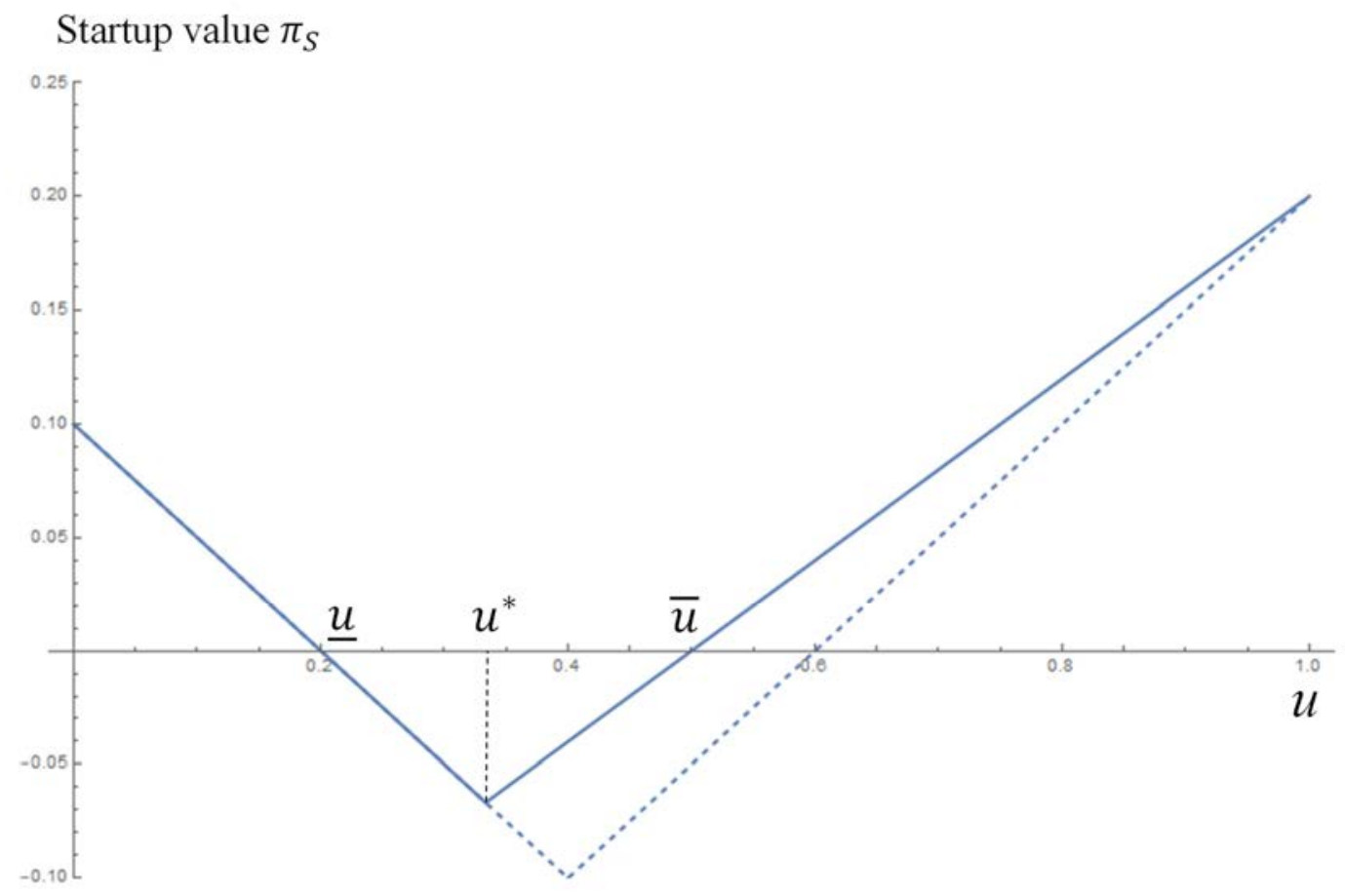




\section{Bargaining power}

We have assumed that the gains from trade are divided equally between the two parties. Consider now the case in which the startup makes a take-it-or-leave-it offer to the closest incumbent with probability $b$, and the incumbents make take-it-or-leave-it offers to the startup with probability 1 $b$. Thus, $b$ parameterizes the bargaining power of the startup. The startup's profit function can be calculated as shown below:

$$
E \pi_{S}(u)=\left\{\begin{array}{ccc}
b(v-C(u))-T(u) & \text { for } & u \leq u^{*} \\
(v-(1+(1-b) \theta) C(u))-T(u) & \text { for } & u>u^{*}
\end{array}\right.
$$

It is easy to show that $\partial E \pi_{S}(u) / \partial b>0$. In other words, an increase in bargaining power always increases the startup's value. Furthermore, the marginal value of an increase in bargaining power increases as $u$ increases, for startups without a viable outside option $\left(u \leq u^{*}\right)$, but decreases with $u$ when the startup has a viable outside option $\left(u>u^{*}\right)$ :

$$
\partial^{2} E \pi_{S}(u) / \partial b \partial u=\left\{\begin{array}{lll}
-\mathrm{C}^{\prime}(\mathrm{u})>0 & \text { for } & u \leq u^{*} \\
\theta \mathrm{C}^{\prime}(\mathrm{u})<0 & \text { for } & u>u^{*}
\end{array}\right.
$$

The implication is that startups caught in the middle are hurt the most by a lack of bargaining power. Figure 3 below illustrates this point. 
Figure 3: Profit function of the startup $\pi_{s}(u)$ when $C(u)=1-u$ and $T(u)=u$. The parameters are $v=1.2, \theta=1, b=1 / 2$ (solid line) and $b=1 / 4$ (dashed line).

\section{Startup value $\pi_{S}$}

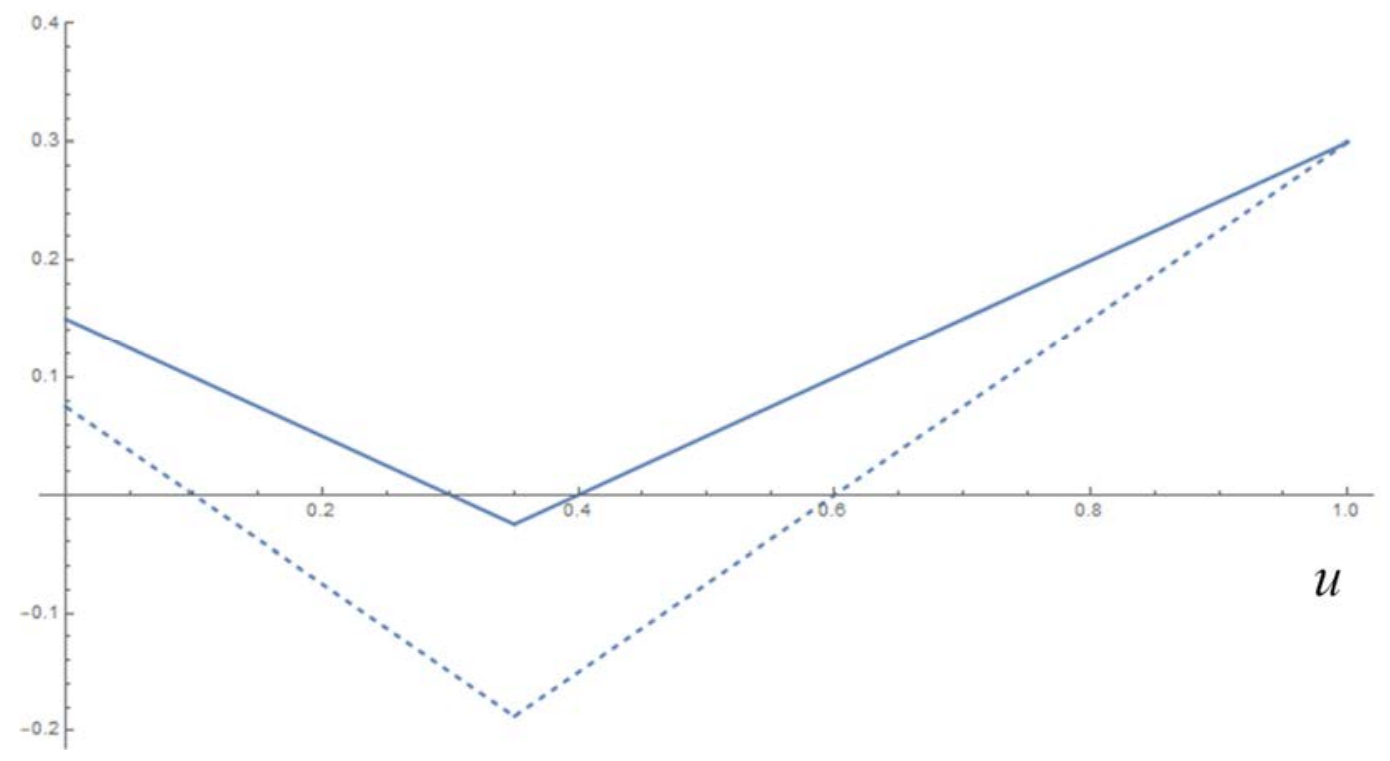

Similarly, we have: ${ }^{2} E \pi_{S}(u) / \partial b \partial \theta=\left\{\begin{array}{ccc}0 & \text { for } & u \leq u^{*} \\ \mathrm{C}(\mathrm{u})>0 & \text { for } & u>u^{*}\end{array}\right.$.

This shows that increased bargaining power and a better outside option are substitutes for startups that have a viable outside option. More precisely, the marginal value of increased bargaining power increases with the startup's comparative disadvantage in solving the commercial challenges and decreases with the number of potential buyers.

\section{Policy interventions}

In the previous section, we demonstrated how startups facing both significant technical and commercial challenges are less valuable. In particular, some of these projects may not be initiated or funded. This raises the question of which policy instruments would be suitable to alleviate the identified failures in the market for startups.

We have treated $u$ as a feature of technological areas that we have implicitly mapped into industries. For example, the cost of drug development tends to be frontloaded (low $C(u)$, high $T(u)$ ) corresponding to a high value of $u$. Even so, the correspondence between industry and technology is imprecise, making it difficult to target policies. Another challenge for targeted policy interventions is the uncertainty regarding the final use for many deep tech innovations. For example, Gore-Tex fibers were initially developed for cables for extreme conditions. However, their main use is in a 
completely different industry, garments and textiles. Finally, in order for policy makers to support only projects that otherwise would not have been undertaken, they would also need to have a deep understanding of the startup's capabilities (cost of solving the commercial challenges) and of the market conditions (number of potential buyers, distribution of bargaining power). While specialized VCs might have this type knowledge, most policy makers probably do not.

In the following, we assume that policy makers do not have the necessary information and insight to make policies conditional on $u$. If this could be done, it would obviously be efficiency-enhancing as there would be no public funds spent on projects that do not require them. We will also assume that there are unfunded projects in the neighborhood of $u^{*}$ as there is otherwise no role for public intervention in our framework.

\section{Subsidies and grants}

Subsidies and grants are commonly used by governments to support innovative activities. One could parameterize a subsidy/grant as an amount $s$ of funds allocated to all projects. This is equivalent to an increase in $v$ inside our model, and it shifts up the startup's profit function for all values of $u$ (see Figure 1). Proposition 2 shows that a subsidy decreases the size of the region around $u^{*}$ in which projects of positive net social value are not privately profitable and thus not funded. Outside of this region, however, the subsidies are transfers from the public to startups and their investors, which may create separate welfare losses.

Some simple algebra shows that:

$$
\partial E \pi_{S}(u) / \partial s=\left\{\begin{array}{lll}
b & \text { for } & u \leq u^{*} \\
1 & \text { for } & u>u^{*}
\end{array}\right.
$$

That is, a subsidy is less effective in increasing the value of the startup on the left of $u^{*}$, where the sensitivity of the value of the startup to a subsidy increases with the startup's bargaining power. Put it differently, a subsidy is more effective when the technical challenges are substantial and startups have weak bargaining power, but less so when most of the challenges are commercial.

Another possibility is a subsidy (or, tax break) that is a fraction of the cost of solving the technical challenges, $T(u)$. This instrument implies a relatively small (large) subsidy to projects characterized by a low (high) value of $u$. Hence, the efficiency of this instrument depends on the value of $u^{*}$, which, in turn, is a function of both the characteristics of the technology and of the market for startups. Without information about $u^{*}$, a policy maker risks spending money on subsidies that have little effect on the formation of deep tech startups. 


\section{Facilitating entry}

Another set of policy instruments aims at facilitating survival and growth of startups and at creating so-called “entrepreneurial ecosystems” (Stam and van de Ven, 2021). Take the example of business incubators and accelerators, which have existed since the late 1950s. Incubators help startups in the early stages with, e.g., developing a business plan and obtaining financing. Business accelerators, on the other hand, tend to help startups at the later stages, closer to commercialization. They may, for instance, connect startups with strategic partners, help them with market research or developing a prototype, and assist them in identifying the right competences and profiles for the management team in order to prepare for scale-up. Initiatives of this type have become an important part of public policy towards entrepreneurship around the world. In our model their effect can be thought of as a reduction in the startup's disadvantage in solving the commercial challenges, $\gamma$. To the extent that the relevant outside option for the startup is solving the commercial challenges by itself, which occurs for instance when there are few potential buyers, these policies reduce the region of $u$ in which the startup earns negative returns, as shown in Proposition 2 and Figure 2. Moreover, such policies are most effective for startups operating in industries around $u^{*}$ where the problem of socially valuable projects yielding negative private returns is most pronounced. One potential downside of these policies is that, though they might improve welfare, they are never used in equilibrium insofar it is efficient to sell the startup. Thus, ex-post evaluations of such policies would indicate insufficient impact.

Innovation procurement by public authorities contains elements of both financial and commercialization support. First, it provides the winning firm with the necessary funds to do R\&D and to develop the business. Second, it opens the market for an application of the technology. A prominent example is the US Defense Advanced Research Projects Agency (DARPA) that supports emerging technologies with awards. These awards have been crucial for the development of many deep tech startups such as the two mentioned in the introduction, iRobot and Biomason.

\section{Direct public investment in startups}

Some countries have government VC funds (GVCs) that invest directly in startups in return for an equity stake. A prominent example is the European Innovation Council (EIC) Accelerator scheme introduced by the European Commission as part of Horizon Europe that, with a budget of several billion euros, is supposed to make equity investments in deep tech ventures during the 2021-27 period. Usually GVC funding comes with some sort of co-investment requirement to minimize crowding-out private investors, and to exploit the comparative advantage of private investors in 
performing due diligence, and providing mentoring and oversight. Since GVCs typically bring less expertise than private VCs, the role of GVCs is ultimately to fill gaps in the supply of private risk capital and perhaps also provide funding below the market rate.

In our model, there are no financing frictions that reduce the supply of private risk capital. Instead, the problem is negative returns for a subset of projects. In this context, GVCs can be effective only insofar as they reduce the cost of capital. Hence, a project may be undertaken even if it results in a negative return. Such a policy can reduce the size of the region around $u^{*}$ in which socially valuable projects fail to get funded. However, if GVCs aim only at increasing the supply of private risk capital, but otherwise behave like private VCs requiring co-investment and positive returns, our model suggests that they are not an effective tool to solve the inefficient functioning of the market for deep tech startups. 


\section{Extensions and robustness checks}

In the following, different extensions and robustness checks are briefly discussed. Details are available from the authors upon request.

\section{Continuous location on the circle}

We have analyzed a variant of the model where the startup with equal probability falls on any point on the circle. The key difference compared to the model presented in Section 2 is that the outside option depends on the realized location. If the startup falls close to the middle between two incumbents, there will be competition among the closest incumbents to acquire the startup. However, if the startup falls close to one of the incumbents, the outside option when negotiating the acquisition price with the closest incumbent is either to solve the commercial challenges by itself (if $C(u)$ is low) or to abandon the project (if $C(u)$ is high).

In this extension, as before, the expected value of the outside option is increasing in $u$. Indeed, as $C(u)$ decreases, the second-closest incumbent bids more aggressively for the startup if it falls close to the middle, and addressing the commercial challenges by the startup itself becomes more profitable if it falls close to one of the incumbents.

We show that the two effects generating the region of $u$ with negative return for the startup demonstrated in Proposition 1 are also at play in this variant of the model. For low values of $u$, the expected value of the startup's outside option when negotiating the acquisition price is low. Since $C(u)$ is high, the startup cannot solve the commercial challenges by itself, and a possible competing offer from another incumbent will be low. While an increase in $u$ improves the expected outside option, this effect is dominated by the holdup problem becoming more severe. Hence, the expected profit of the startup is decreasing in $u$ for low values of $u$. For higher values of $u$, the expected outside option of the startup is good, and here the improved bargaining position associated with an increase in $u$ outweighs the amplification of the holdup problem. Therefore, profits are increasing in $u$ for $u$ sufficiently large.

Summing up, while a model with continuous location on the circle requires additional analysis due to the startup's outside option being stochastic, the basic logic and results of the model remain. 


\section{Investment by an incumbent}

We have explored a variant of the model with a single incumbent capable of solving the technical challenges. In particular, conditional on investment $T(u)$, the incumbent succeeds in solving the technical challenges with probability $q$ whereas the startup succeeds with probability 1 . It is assumed that $q \leq \frac{1}{2}$, which implies that the startup's comparative advantage in solving the technical challenges is sufficiently large. While the startup is able to solve the commercial challenges for $u>$ $u^{*}$ (i.e. when $C(u)$ is low), we assume that it cannot profitably compete with the incumbent. Hence, the timing is as follows. The two firms decide simultaneously whether to invest or not to solve the technical challenges. If the incumbent invests and is successful in solving the technical challenges, it also solves the commercial challenges, and the startup abandons its project. If the startup is the only firm to solve the technical challenges, either because the incumbent is unsuccessful, or because the incumbent does not invest, the game proceeds as in the baseline model.

We show that both the startup and the incumbent have lower incentives to solve the technical challenges when the other firm invests, which may cause multiple equilibria to exist. The startup's incentives to invest are lower when the incumbent invests because the incumbent's investment may make the startup's project redundant. Similarly, the incumbent's incentives to invest are lower when the startup invests because it can also profit from commercializing the startup's project instead of its own.

We show that our main results carry over to this extension. In particular, there is a neighborhood around $u^{*}$ in which no firm invests in solving the technical challenges when the rate of return $(v-[C(u)+T(u)]) /[C(u)+T(u)]$ is low. However, allowing the incumbent to solve the technical challenge does modify some of the results. First, for low values $u$, both firms invest as the cost of solving the technical challenges is low. Second, if the incumbent's ability to solve the technical challenges is sufficiently high $(1 / 3<q \leq 1 / 2)$, multiple equilibria may arise in an interval of $u$. In this interval, both firms are willing to invest $T(u)$ but only if the other firm does not invest. ${ }^{11}$ Our model does not predict which equilibrium arises in this situation. However, if we would introduce sequential moves, the first-mover would choose to invest in solving the technical challenges. For example, university spinouts may have the first-mover advantage and be the ones investing for deep tech growing out of university research.

\footnotetext{
${ }^{11}$ In addition, there is an equilibrium in mixed strategies where the firms invest with a positive probability.
} 


\section{Uncertainty regarding the cost of solving the commercial challenges}

Uncertainty regarding the value created is an important feature of all innovation projects, and this is particularly true for deep tech. We have ignored uncertainty so far in order to illustrate the main mechanism in the simplest possible way. In this extension, uncertainty is introduced in order to illustrate how it moderates our results. Below, only uncertainty regarding the cost of solving the commercial challenges is considered, but uncertainty regarding the value of the project has very similar effects.

Suppose that the realized cost of solving the commercial challenges is $C(u)+\Delta$ with probability $1 / 2$ and $C(u)-\Delta$ also with probability $1 / 2$. We assume that $C(u)+\Delta<v$ so that no project is abandoned after the cost of solving the commercial challenges is realized. Hence, there is no option value associated with investing in solving the technical challenges from the point of view of social welfare.

If $(C(u)-\Delta)(1+\theta) \geq v$, uncertainty does not matter. The (expected) value of the startup is given by equation (1). Similarly, if $(C(u)+\Delta)(1+\theta) \leq v$, the expected profit of the startup is given by equation (2). However, if $(C(u)-\Delta)(1+\theta)<v<(C(u)+\Delta)(1+\theta)$, uncertainty makes a difference. The expected value of the startup is now:

$$
\begin{gathered}
\pi_{S}(u)=\frac{1}{2} * \frac{1}{2}(v-C(u)-\Delta)+\frac{1}{2}\left(v-(C(u)-\Delta)\left(1+\frac{\theta}{2}\right)\right)-T(u)= \\
\frac{3}{4}\left(v-C(u)\left(1+\frac{\theta}{3}\right)\right)+\frac{\Delta(1+\theta)}{4}-T(u) .
\end{gathered}
$$

Notice that introducing uncertainty does not change the expected social value of the project as it only affects the distribution of the value created. This case can only arise for $\underline{u}^{*} \leq u \leq \bar{u}^{*}$ where the thresholds are defined as:

$$
\underline{u}^{*} \equiv c^{-1}\left(\frac{v}{1+\theta}+\Delta\right) \text { and } \bar{u}^{*} \equiv c^{-1}\left(\frac{v}{1+\theta}-\Delta\right)
$$

We assume that the parameters are such that $0<\underline{u}^{*}<\bar{u}^{*}<1$.

Proposition 3. Uncertainty regarding the cost of solving the commercial challenges leads to a strict increase in the startup's expected profit compared to a situation with no uncertainty for $\underline{u}^{*}<u<$ $\bar{u}^{*}$. 


\section{Proof: See Appendix A.}

The intuition behind Proposition 3 is that the profit of the startup is convex in $u$ around $u^{*}$. Hence, the convex combination of the profits for $u_{L}$ and $u_{H}$ where $u_{L}<u^{*}<u_{H}$ is greater than the profit for the equivalent convex combination of $u_{L}$ and $u_{H}$. Figure 4 illustrates this point. Put differently, uncertainty regarding the cost of solving the commercial challenges alleviates the problem of startups caught in the middle. Intuitively, once the technical challenges have been solved, uncertainty provides startups with the possibility to solve the commercial challenges themselves with some probability. Notice, however, that uncertainty about the cost of solving the technical challenges, $T(u)$, does not have any effect on the expected value of the startup.

Figure 4: The expected profit with uncertainty (solid) and without uncertainty (dashed) when $C(u)$ $=1-u$ and $T(u)=u$. The parameters are $\theta=1, v=1.2$ (solid line), and $\Delta=0.1$.

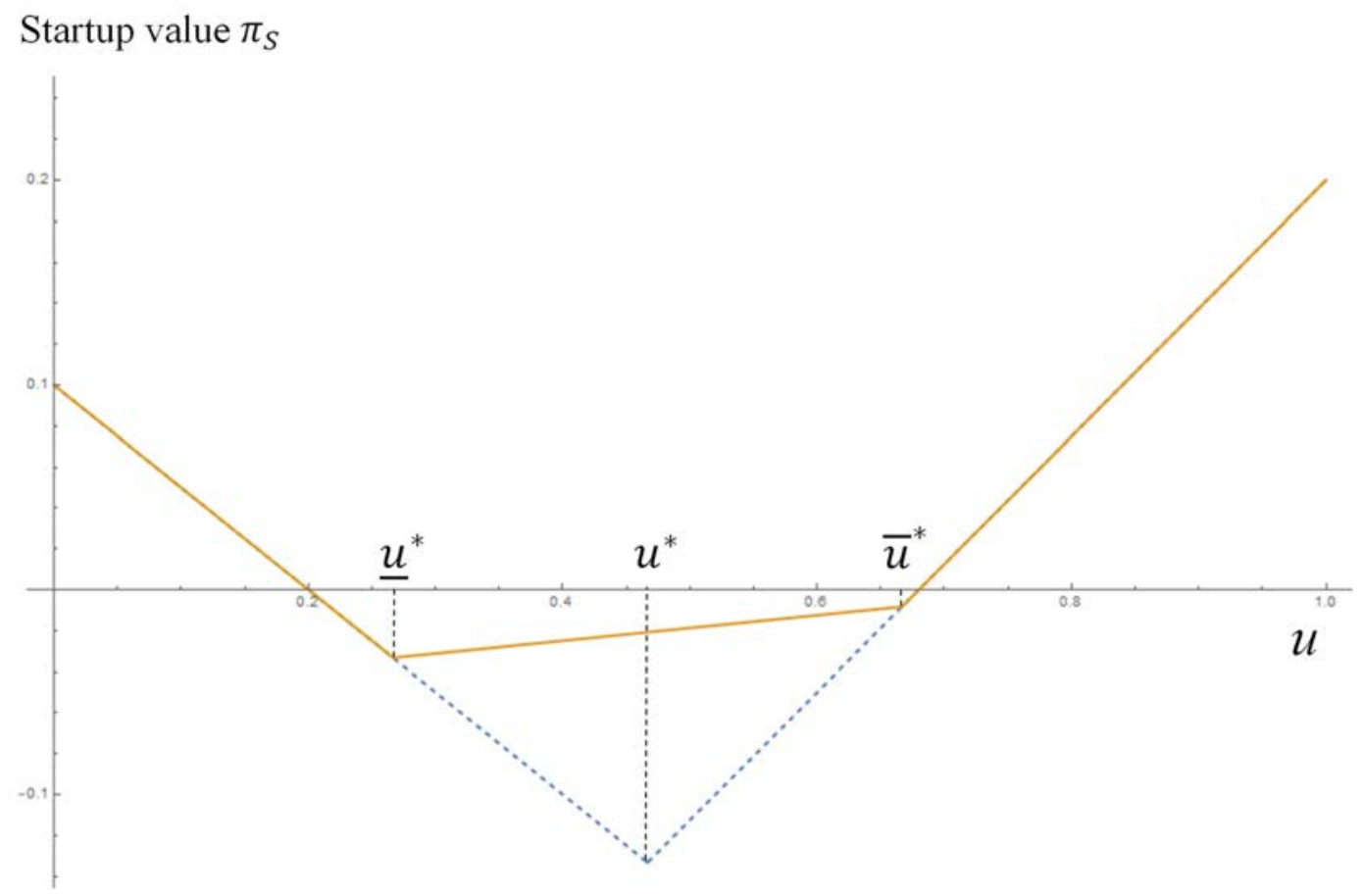

\section{Conclusion}

By applying complex technologies rooted in science and advanced engineering to some of society's most pressing problems, deep tech innovation promises to bring a large array of new, radical advances to the marketplace. However, set aside a few notable exceptions, deep tech innovation has 
not delivered up to expectations. Scholars and practitioners alike have suggested that, despite the exuberant VC industry, deep tech innovation has failed to attract sufficient risk capital.

In this paper, we develop a parsimonious theoretical model that provides an intuitive yet novel explanation to this puzzle: Deep tech startups do not receive sufficient funding because, other things equal, they are privately less valuable relative to the total value they create.

Many deep tech inventions, given their strong dependence on science and basic research, are initiated in startups, especially university spinoffs. However, startups often lack the complementary assets that are required to scale up and commercialize such technologies. Complementary assets are typically owned by incumbents. Thus, an efficient market for deep tech startups would bring important welfare benefits. Our analysis shows that such a market for startups does not work well when technologies display both technical and commercial challenges, which is typical of deep tech innovation. Startups that develop projects which entail both types of challenges are "caught in the middle” when negotiating the acquisition price with an incumbent. The upfront investment in addressing the technical challenges exposes them to holdup problems and the follow-on investment in solving the commercial challenges mutes the threat of the startup commercializing the technology itself. This results in a low acquisition price for the startup relative to the societal value created by the technology. Thus, an innovation ecosystem, where startups develop new inventions, often based on university discoveries, and incumbents acquire the inventions and commercialize them, which has worked well in many areas of the economy in recent decades (Arora et al., 2020) is unlikely to deliver the holy grail of deep tech innovation.

In the analysis, the composition of costs has been considered an inherent characteristic of the technology area and thus exogenous. However, to the extent that startups choose among projects, they will seek out project that mainly involve one type of risk, compounding the problem analyzed in this paper.

Our results also highlight the policy challenges of enhancing deep tech innovation. Although grants and subsidies, and subsidized investment in deep tech startups can be useful, so can policies improving the startups’ commercialization capabilities. By increasing the commercialization alternatives open to a startup, these policies help the startup to achieve a higher acquisition price, alleviating the problem of the insufficient value capture. Still, these policies may appear ineffective to the general public as they do not result in startups entering the markets and competing. 
This paper contains one of the first attempts to analyze issues pertinent to deep tech using formal modelling. Still, there are clearly important issues that are not addressed here. For example, the consolidation of market power resulting from tech giants acquiring promising high-tech startups is high on the policy agenda in many jurisdictions (Cunningham et al., 2021; Fumagalli et al., 2020). Whether this concern applies equally to deep tech startups is an interesting question. Deep tech startups aim for major breakthrough that potentially could make the market position of the acquiring firm difficult to challenge. At the same time, we know from early work of Gilbert and Newbery (1982) that the incentives for incumbents to preempt competition is weaker for radical innovations. Another issue concerns the access to complementary services such as contract development and manufacturing for biotech startups and cloud computing for IT startups. To the extent that such services are less developed in the areas of deep tech, this would make it harder for deep tech to pursue own commercialization (corresponding to a higher value of $\theta$ inside our model), weaken their bargaining position vis-à-vis potential acquirers, and exacerbate the financing problem that deep tech startups face. We leave these and other issues for future research. 


\section{References}

Arora A., Belenzon S., Patacconi A., Suh J. 2020. The changing structure of American innovation: Some cautionary remarks for economic growth. Innovation Policy and the Economy 20(1): 39-93.

Arora A., Fosfuri A., Gambardella A. 2001. Markets for Technology: The Economics of Innovation and Corporate Strategy. MIT Press: Cambridge, MA.

Arora A., Fosfuri A., Roende T. 2021. Waiting for the payday? The market for startups and the timing of entrepreneurial exit. Management Science 67(3): 1453-67.

BCG. 2021. Investment Paradox: a call to redesign the investor model. Hello Tomorrow. Boston Consulting Group.

Binmore K., Rubstein A., Wolinsky A. 1986. The Nash Bargaining Solution in Economic Modelling Rand Journal of Economics 17(2): 176-188.

Cunningham C., Ederer F., Ma S. 2021. Killer acquisitions. Journal of Political Economy 129(3): 649-702.

Ewens M., Nanda R., Rhodes-Kropf M. 2018. Cost of experimentation and the evolution of venture capital. Journal of Financial Economics, 128(3): 422-442.

Färnstrand Damsgaard E., Hjertstrand P., Norbäck P.J., Persson L., Vasconcelos H. 2017. Why Entrepreneurs Choose Risky R\&D Projects - But Still Not Risky Enough. The Economic Journal 127(605): F164-F199.

Fischer M., Henkel J., Stern A.D. 2020. Pioneer (dis-) advantages in Markets for Technology. HBS Working Paper. Available at https://papers.ssrn.com/sol3/papers.cfm?abstract_id=3362959

Fumagalli C., Motta M., Tarantino E. 2020. Shelving or Developing? The Acquisition of Potential Competitors Under Financial Constraints. CEPR Working Paper. Available at SSRN: https://ssrn.com/abstract=3674889

Gans J., Hsu D., Stern S. 2002. When Does Start-Up Innovation Spur the Gale of Creative Destruction? RAND Journal of Economics 33(4): 571-586.

Gilbert R., Newbery D.M. 1982. Preemptive Patenting and the Persistence of Monopoly. American Economic Review 72(3): 514-26.

Green J.R., Scotchmer S. 1995. On the Division of Profit in Sequential Innovation. RAND Journal of Economics 26(1): 20-33.

Henkel J., Rønde T., Wagner M. 2015. And the winner is-Acquired. Entrepreneurship as a contest yielding radical innovations. Research Policy 44(2): 295-310.

Higgins M., Rodriguez D. 2006. The outsourcing of R\&D through acquisitions in the pharmaceutical industry. Journal of Financial Economics 80(2): 351-383.

Holmstròm B., Tirole J. 1997. Financial Intermediation, Loanable Funds, and the Real Sector. Quarterly Journal of Economics 112(3): 663-691. 
Janeway W.H. 2018. Doing Capitalism in the Innovation Economy: Markets, Speculation and the State. Cambridge, UK: Cambridge University Press.

Janeway W.H., Nanda R., Rhodes-Kropf M. 2021. Venture Capital Booms and Start-Up Financing. Annual Review of Financial Economics 13: 11-127.

Lerner J., Nanda R. 2020. Venture capital's role in financing innovation: what we know and how much we still need to learn. Journal of Economic Perspective 34(3): 237-61.

Nanda R. 2020. Financing Innovation “Tough Tech”. In The Global Innovation Index. Chapter 5: 113-19.

Ransbotham S., Mitra S. 2010. Target Age and the Acquisition of Innovation in High-Technology Industries. Management Science 56(11): 2076-2093.

Stam E., van de Ven, A. 2021. Entrepreneurial ecosystem elements. Small Business Economics 56: 809-8.

Tirole J. 1988. The theory of industrial organization. MIT Press. Cambridge, MA. 


\section{Appendix: Proof of the propositions in the main text}

Proof of Proposition 2: Introducing $(1+\beta)$, we have that $u^{*}$ is defined as $u^{*}=C^{-1}\left(\frac{v}{(1+\theta)(1+\beta)}\right)$. Total differentiating this expression, we have:

$$
\begin{gathered}
\frac{d u^{*}}{d v}=\frac{1}{(1+\theta)(1+\beta) C^{\prime}\left(\frac{v}{(1+\theta)(1+\beta)}\right)}<0, \\
\frac{d u^{*}}{d \theta}=-\frac{v}{(1+\theta)^{2}(1+\beta) C^{\prime}\left(\frac{v}{(1+\theta)(1+\beta)}\right)}>0, \\
\frac{d u^{*}}{d \beta}=-\frac{v}{(1+\beta)^{2}(1+\theta) C^{\prime}\left(\frac{v}{(1+\theta)(1+\beta)}\right)}>0 .
\end{gathered}
$$

Turning $\underline{u}$, it is defined implicitly by $\frac{1}{2}(v-(1+\beta) C(\underline{u})-(1+\beta) 2 T(\underline{u}))=0$. Total differentiating this expression, and using $C^{\prime}(u)+T(u)=0$, we have:

$$
\frac{d \underline{u}}{d v}=\frac{1}{T^{\prime}(\underline{u})(1+\beta)}>0 \text { and } \frac{d \underline{u}}{d \beta}=-\frac{C(\underline{u})+2 T(\underline{u})}{T^{\prime}(\underline{u})(1+\beta)}<0 .
$$

Notice that $\theta$ does not enter the equation defining $\underline{u}$, and thus $\frac{d \underline{u}}{d \theta}=0$. Finally, $\bar{u}$ is defined implicitly by $v-(1+\beta)\left(C(\bar{u})+T(\bar{u})+\frac{\theta}{2} C(\bar{u})\right)=0$. Total differentiating this expression, we have:

$$
\frac{d \bar{u}}{d v}=\frac{2}{\theta C^{\prime}(\bar{u})}<0 \text { and } \frac{d \bar{u}}{d \theta}=-\frac{C(\bar{u})}{\theta C^{\prime}(\bar{u})}>0 \text { and } \frac{d \bar{u}}{d \beta}=-\frac{C(\bar{u})\left(1+\frac{\theta}{2}\right)+T(\bar{u})}{(1+\beta) \frac{\theta}{2} C^{\prime}(\bar{u})}>0 .
$$

This completes the proof of Proposition 2.

Proof of Proposition 3: The profit of the startup is $\frac{3}{4}\left(v-C(u)\left(1+\frac{\theta}{3}\right)\right)+\frac{\Delta(1+\theta)}{4}-T(u)$ with uncertainty and $\operatorname{Max}\left\{\frac{1}{2}(v-C(u))-T(u), v-C(u)\left(1+\frac{\theta}{2}\right)-T(u)\right\}$ without uncertainty, see equations (1), (2), and (4). Simple calculations show: 


$$
\begin{gathered}
\frac{3}{4}\left(v-C(u)\left(1+\frac{\theta}{3}\right)\right)+\frac{\Delta(1+\theta)}{4}-T(u) \\
>\operatorname{Max}\left\{\frac{1}{2}(v-C(u))-T(u), v-C(u)\left(1+\frac{\theta}{2}\right)-T(u)\right\} \Leftrightarrow \\
(C(u)-\Delta)(1+\theta)<v<(C(u)+\Delta)(1+\theta),
\end{gathered}
$$

which proves the proposition. $\square$ 